\title{
Planning for Claims: An Ethnography of
}

\section{Industry Culture}

John Rooke, David Seymou \& Richard Fellows

Published as:

Rooke, J., Seymour, D. \& Fellows, R. (2004) 'Planning for Claims; An Ethnography of Industry Culture’, Construction Management and Economics, 22:(6)655-662. 


\title{
Planning for Claims; An Ethnography of Industry Culture
}

\begin{abstract}
Claims by contractors for additional payments have been identified by commentators as a major source of difficulty in the industry. Ethnographic research with industry members reveals some key features of planning practices that underlie such events. Claims are sometimes planned at tender stage and sometimes during the course of a project. One practice at tender stage is a pricing technique that minimises the tender price while maximising the out-turn cost of a contract by exploiting mistakes in the bill of quantities. Another is the programming of work to maximise its vulnerability to delay. More reactive techniques may be employed during the course of the project, often to make up for an unanticipated increase in costs.

These and other similar practices may be reported as features of an integrated culture, defined in such a way as to encompass activity and reject Cartesian dualism. The unique adequacy requirements of methods are suitable criteria for the evaluation of such reports.

The claims culture arises from economic conditions in the industry which include low entry barriers and competitive tendering. However, removal of these conditions alone cannot guarantee that the practices will cease.
\end{abstract}


Keywords: Procurement; Claims Management; Organisational Culture;

Ethnography; Ethnomethodology. 


\section{Introduction}

It is a widely held view that the culture of the UK construction industry is opportunistic, prone to conflict and resistant to change and that these characteristics impede competitiveness and overall efficiency. Latham referred to "a culture of claims" and noted, "the industry has deeply ingrained adversarial attitudes [...] the culture of conflict seems to be deeply embedded” (Latham 1993, p5). It is argued that price competitive tendering has resulted in a habitual tendency amongst contractors to expend more effort on generating profit from claims than from improved construction methods.

The concept of organisational culture has become widely recognised as an integral part of any comprehensive approach to management theory and practice, particularly when organisational change is at stake (Robbins 2001, Senior 2001). The assumption is that if radical technological and organisational improvements are to be achieved, culture and how to make it receptive to these changes constitute a big challenge. Thus, while the planning practices described in this paper can be seen as a rational response to economic conditions, their eradication cannot be achieved by simply removing those conditions. The reasons for this should be apparent from the ethnography and discussion below.

An agreed definition of culture remains elusive (Brown 1995, Senior 2001). This paper adopts an ethnographic approach which relies on a long standing definition from the field of anthropology.

"Culture, or civilization, taken in its wide ethnographic sense, is that complex whole which includes knowledge, belief, art, morals, law, custom, and any other capabilities and habits acquired by man as a member of society.” (Tylor 1913, p2) 
This definition specifically includes a behavioural aspect that is excluded from many narrower definitions (cf. Hofstede 1980) and facilitates an ethnographic approach which allows for the literal description of actual practices, in preference to a statistical presentation of indicators referring to an underlying theoretical construct. The latter approach assumes an understanding of the cultural formation to be investigated and attempts to measure its prevalence. A number of papers of this type have recently appeared in the construction management literature (cf. Fisher \& Ranasinghe 2001, Tam, Fung \& Chan 2001). In contrast, the intention in this study is to achieve a deeper understanding of the culture, leaving the question of its prevalence as a matter for managers to decide in practice. There are several reasons for adopting this approach. First, severe theoretical reservations have been expressed regarding attempts to measure culture (Seymour \& Rooke 1995). Second, research into covert practices, such as those described here, requires a degree of tact, flexibility and depth of approach that presents peculiar obstacles to the application of questionnaires and other survey approaches. Third, this type of finding may be more immediately relevant to managers' practice.

\section{Methodology}

Ethnography, or participant observation, is a research practice in which a researcher enters a setting, say a site meeting, or an estimating department, and learns about it principally through the instruction of other members of those settings. It has been argued that this practice represents a paradigmatic shift from the formal research methods that are conventionally employed in construction and project management research (Seymour \& Rooke 1995). While others suggest that the two paradigms may be successfully merged (Raftery, McGeorge \& Walters 1997), ethnography 
remains a minority pursuit in construction and project management and one which is still often regarded with suspicion.

A major reason for this may be the difficulty of establishing clear criteria of adequacy for ethnographic findings. That competing sets of criteria exist, can create confusion. The report which follows is designed to meet one such set, derived from ethnomethodological studies (henceforth EM). It consists of the unique adequacy requirements of methods (Garfinkel \& Wieder 1992, Garfinkel 2002). These criteria are founded on the principle that the activities and procedures of persons in a setting can best be accounted for in terms of the understandings that those persons have of that setting. Thus, the task of the ethnographer is to render a clear description of those understandings, rather than offer an explanatory theory.

There are two unique adequacy requirements, a weak one and a strong one. The weak requirement is that:

"the analyst must be vulgarly competent in the local production and reflexively natural accountability of the phenomenon" (Garfinkel \& Wieder 1992, p182)

Thus, to analyse a management setting adequately, we must know what any member of that setting would ordinarily know about that setting. This can be regarded as a criterion for adequate ethnography. Thus, the ethnographer can produce an adequate account only to the extent that s/he appreciates the understanding of the setting which any other member of that setting would have. The question of whether that understanding has been achieved is a matter for the judgement of any other competent participant.

A properly EM account should also meet the strong requirement of unique adequacy. The strong requirement is founded on the principle that the methods of analysis used 
to describe a setting should be derived directly from that setting. This assumes that the methods which participants in a setting use to make their meanings clear to others, are sufficient to the purpose of producing an account of that setting. Furthermore, the use of any other methods to describe that setting must involve some distortion. It would involve the researcher introducing a theoretical account alien to the setting's members. Note that the strong requirement involves a decision to exclude from the ethnography any judgements as to the effectiveness or efficiency of participants practices, unless these originate from and are attributed to participants.

A consequence of the application of the strong criterion of unique adequacy is that studies of work can be categorized according to whether or not the ethnographer has allowed his own preconceptions or theorising to intrude into the study.

We believe that the application of these principles constitutes a rigorous test for the empirical status of ethnographic findings and enables a clearer separation than is usual between findings on the one hand and theory and recommendation on the other. Thus, the body of this paper consists of an ethnographic report designed to conform to the strong requirement of unique adequacy. This is followed by a discussion and conclusion which attempt to contextualise the findings within the broader context of the industry and the changes it is currently undergoing. In line with our commitment to the strong requirement of unique adequacy, we refrain from attempting to constructively interpret, or extrapolate from our findings; an activity that is perhaps best left to our readers.

The data was primarily generated from unstructured interviews. The essence of effective ethnographic interviewing is to establish a relationship in which the 
informant/interviewee takes the role of teacher and the researcher/interviewer, that of student (Spradley 1979).

In line with this objective, the technique used in interviews was simply to encourage the interviewee to talk on the subject of contract administration (usually with direct reference to the project on which they were currently engaged) with a minimum of direction from the interviewer. The data were originally collected as part of a project to examine the impact of cultural issues on the introduction of the Engineering and Construction Contract (NEC). Thus, when the interview was initially arranged, participants were usually told one of two things, depending on whether they were involved in the administration of an NEC contract themselves. If they were, they were informed that the researcher was interested in how they were finding working on the new contract. If not, they were told of the interest in the NEC and that the researcher wanted to 'look at other contracts for comparison'. Interviews began with an open ended question, asking for a comparison between the NEC and other contracts, or for the interviewee to talk about their problems with contract administration.

Through this undirective interview technique, the research sought to operate at Mishler's (1986) first level of empowerment of informants: seeking to report their points of view with minimal distortion. At all times, the researcher sought "to understand and allow for the interconnections and mutual influence between the researcher and those being researched” (Heyl 2001, p.377).

Direct observation of meetings was also carried out on two of the projects. All interviews were recorded using audio tape, supplemented by field notes. Direct observation was usually recorded using field notes only. 
Direct observation and unstructured interview together make up the participant observation method. The two are interwoven and complementary and there is no firm distinction between them. In order to observe a setting the researcher must enter into that setting. In doing so, the researcher becomes part of the setting under observation. Seeing (and crucially hearing things, since observation like other social activities, is largely done through talk) the researcher asks for clarification. In this way, the observation is active; the observer is a participant. Similarly, interviews are carried out with people at their place of work; they do not involve removing the setting's participants from the context in which their activities normally take place. Thus, they allow the interviewer to witness the informant at work (interruptions to the interview, thus being welcomed as opportunities for further insight). Conversely, they afford informants the opportunity to demonstrate their meaning with direct reference to the feature of the setting (for example: drawings, computer programmes, contractual documents, or elements under construction).

The rich data that is thus rendered available to the researcher is available for crossreference in complex ways that defy formal description, but has been characterised by Garfinkel as 'documentary method'. Thus, for instance, the technique of programming work to take place immediately following work by statutary undertakers was initially explained to the researcher in an interview. The consequences of such programming were later observed on a project entirely unconnected with the original informant. On other occasions, interview data, or data from direct observation, has become the topic of brief follow up interviews (often just a phone call) which have enabled us to clarify and test our understandings with our 
informants.

The findings are a product of ethnographic research across seven construction projects and additional interviews with members of the industry. The projects constituted a variety of building and civil engineering projects, ranging in value from $£ 1.5 \mathrm{~m}$ to $£ 60 \mathrm{~m}$. The interviews produced 45 hours of audio tapes, including 18 hours with individuals not directly concerned with the seven projects. Eight site meetings were attended on one project, four on another. The taped interviews and observations of meetings were supplemented by considerable informal contact with participants on three of the projects and by telephone conversations with project participants and others.

Finally, in this section, a note on theory. The strong requirement of unique adequacy excludes the imposition of any preconceived analytic framework on our findings. Notably, this leads to a rejection of the currently dominant view that culture should be defined abstractly, as a non-physical phenomenon, analytically separable from the settings in which it occurs (Brown 1995, Martin 2002). This is no place for an ontological debate, we merely note some of the antecedents of this position in the work of Descartes (1937), Parsons (1951) and Levi-Strauss (1977) and its rejection in the work of Wittgenstein (1958), Ryle (1963), Garfinkel (1984) and Winch (1990). On the other hand, Martin's (2002) enunciation of integration, differentiation and ambiguity perspectives provides useful further context to the findings reported here. Our account of the claims culture is given from an integration perspective, inasmuch as it is restricted to a description of established methods of designing and executing claims. However, it is evident that these methods are not universally recognised within the industry, that they are often highly contentious in the settings in which they are employed and that the type and degree of planning involved in the design of any 
particular claim is never explicit at the time of its execution. Without doubt, therefore, differential and ambiguous features of the claims culture remain to be explored elsewhere. Their meagre treatment in the present account is attributable solely to lack of space.

\section{The Economics of Contracting}

The economics of contracting are sometimes a puzzle to those outside the industry. Profits of three or four percent on turnover do not look viable to those conditioned to expect a relatively long term investment of capital. However, the labour intensive nature of the construction industry means that there is little need for long term investment. Thus, a high rate of turnover can produce substantially greater return on capital. In consequence, return on capital is much greater than percentage mark-up on (forecast) cost which is extended by changes invoking reductions in capital utilised; notably, more extensive subcontracting.

Furthermore, as Hillebrandt and Cannon (1990) have observed, profits are further boosted by management of cash flow. Speed of capital circulation (reinvestment) occurs via effective management of credit and cash flow and facilitates viable levels of profitability. They do not explore the methods by which this is achieved. However, these are well known in the industry. A system of interim payment by clients, combined with delays in payment to sub-contractors and suppliers creates a favourable cash flow situation for the main contractor. In this way, contractors can generate capital for other businesses, such as house building. 
The situation is made more complex by a tendering strategy adopted by contractors. This strategy is described in more detail in the ethnography. It involves submitting tenders at prices which reflect the expectation that the ultimate price of the job will be inflated by claims. As will be seen, there is no element of speculation in this approach. Claims are carefully planned and the value of the expected return is calculated with a degree of accuracy which allows the contractor to submit tenders at prices which, if quantities were to remain unchanged, would render a negative profit. This strategy of planning for claims has the effect of creating barriers to entry into the market. In an industry with such low capitalisation, the threat of new players undercutting established firms is always severe. However, only large contractors can afford to employ the numbers of staff, of sufficient levels of expertise, needed to successfully manage claims on the scale needed to turn what might be an apparent twenty-five percent loss into a profit of three or four percent. This means that smaller contractors who attempt bids can be eliminated at tender stage. However, the resulting disputes between contractors and clients, have done much to contribute to the industry's negative image.

A further problem is generated by the combined effects of the two elements of the contractors' approach; in the face of mounting claims, clients will often refuse, or delay payments; sometimes for several years. Since contractors need to maintain positive cash flow in order to maintain profitability, they experience further pressure to withhold payments from sub-contractors and suppliers. This is despite contractual provisions (some of which may actually be employed to enhance or excuse delays) and recent legislation to eliminate 'pay when paid' terms.

What seems to emerge is considerable support for behaviour characterised in transaction cost economics (e.g. Williamson, 1985). That paradigm operates through 
bounded rationality, asset specificity and opportunism; commonly couched in terms of informational issues. Thus, Dietrich (1994:33) notes that transaction costs may be defined in 'terms of three factors: search and information costs, bargaining and decision costs, and policing costs'. Given the growth in subcontracting, the construction industry is increasingly concerned with transaction costs rather than the (alternative, internal) organisation costs. The incidence of claims may be characterised readily in terms of the transaction costs paradigm (often overtly opportunistic, in situations of specialist information and with major presence of asset specificity); the 'Dutch auctioning' of letting subcontracted work extends and is likely to accentuate the situation. It appears that the usual ex post procedures are inadequate to deal with the matter and so, attention should be devoted to ex ante possibilities.

\section{Ethnographic Findings}

\section{Proactive Claims: planning for claims at tender stage}

An important element in the contractor's approach is the planning for claims at tender stage. This section contains a description of two methods by which claims are designed at tender stage and of the context in which they applied.

The first of these methods is concerned with pricing the bill of quantities.

Measurement is central to the contracting process. As one engineer, an estimator for a large contractor put it: 
"contracting is all about pricing in accordance with the conditions of contract, in accordance with the specifications, in accordance, more than anything, with the method of measurement. And if it says, if on a job there are ten measurements and somebody's only measured three of them, you don't point it out to them, you price the three. You know, whack it up. So when you measure the ten you get some profit. And you anticipate that profit off the profit you add on to the simple mark up. So you may even go into a tender with a negative profit, knowing it's going to come out, because it will be measured properly eventually by somebody and you'll recover it.”

This short passage summarises the essence of the estimator's work. Pricing a tender involves reading through bills of quantity often several inches thick, pricing the individual quantities and thus coming to a total cost for the job. The art of his work is in spotting mistakes which can then be exploited. As he describes above, when he anticipates that the quantities needed will be greater than those specified in the bill, he charges more for them. Thus, for a relatively low increase in the tender price, he can generate a considerable profit when the quantities are re-measured. Similarly, when he anticipates a reduction in the quantities needed, he charges less. He might even charge nothing for a particular item. This means that he will submit the lowest possible tender price, with a minimal effect on the anticipated out-turn price.

A second method of designing claims centres on the programme for the work. Thus, programmes are designed in order to anticipate and maximise the cost of delays. An engineer working for another large contractor gave the following example:

"if you know the client is going to have to arrange for a water main to be diverted or something like that, you always programme the work you have to do when that water main is diverted, you're going to do it straight away, as 
soon as it's diverted. Because you know as sure as eggs is eggs, water companies never finish on time.”

The client will be liable for the cost of the subsequent delay.

In selecting which jobs to tender for, contractors may deliberately seek out those most likely to yield claims. Jobs are sometimes chosen for their complexity. The estimator quoted above said of one job:

"that was carefully chosen by us as a target. The fact is that in construction, the only way to make a profit is when a contract goes wrong. The mark ups necessary to win the job are negative and therefore something has to change. That one, there are ten civil contracts and five major M\&E contracts. Now the ten civil contracts, they go to A to B, you've got ten jobs; but the M\&E jobs go right the way through and you've got five of those interfacing with ten of those. A recipe for disaster.”

However, the degree to which the design, planning, or measurement is seen to be badly executed, is a major factor in determining the possibilities for planning claims. The estimator described a job of this type. The company was given five days to produce a tender and eventually came up with a price of £148,000. However, "We had two amendments and then a phone call. The phone call says, 'By the way, we've now changed the side slope to this cutting'. I mean all it was, was a more or less circular shape where we're cutting into the bank, leave some muck there and make it higher in the middle. That was what the job was. They hadn't even got the bloody side slope organised and they changed it from the day they post it out. Five days to price it, two amendments in those five days, I mean come on. There's opportunity for you.” 
The estimator described a highly systematic approach to the planning of claims. It is impossible to say with certainty how widely this approach is practised. No other informant confirmed this picture of the systematic nature of planning for claims. It is likely that many of them were not aware of it, as the estimator observed,

“they don’t tell you these things to start with, y’know when you start off. I was a freelance, I was doing a job for them, so I knew what I had to do, I had to represent them. An' then gradually as an estimator you price it and you go in to the final briefing and gradually you understand. And then you start and then you realise that pricing the job is worth, y'know about half of it, the rest of it is, in depreciating degrees.”

\section{Reactive Claims: developing claims during a project}

However widespread the practice of planning for claims at tender stage, it is clear that many claims are planned in the course of a project itself, in response to unforeseen events. Indeed, as one contractor's engineer observed,

"If you get to the end of a job and you've made a loss, you look at bloody everything, to see if there are any commercial opportunities you've missed.”

Some claims strategies can be far more opportunist than this. One device is to move any idle plant and labour onto a job where a delay is anticipated. Thus, when the delay occurs, the contractor is able to claim day rates for the idle resources. On occasion, this strategy has been employed to an absurd degree. Thus, one contractor told of arriving at the office one morning to find that every piece of obsolete and derelict plant was being moved out. When he asked what was going on, he was told that the whole lot was being transferred to a project which was about to suffer a major delay. In a situation like this it is impossible to ascertain how far in advance the claim had been planned. However, in other cases it is very clear. Below, two 
examples of claims which were planned in the course of a project are considered. These are both taken from a single contract, a £3m construction project on a brownfield site and both originated in response to an anticipated loss by the contractor.

The location had previously been the site of a brewery which had been demolished. A ground test showed a filled site with few obstructions and the job was put out to tender on the basis that the contractor should design foundation piles and take responsibility for ground conditions. Once work had started however, it became clear that the ground test report was seriously misleading; a four inch thick yorkstone slab extended over virtually the whole site, at a depth of three and a half metres. Most of the boreholes drilled for the ground test had been sunk to depths of less than three and a half metres; those few that went deeper had missed the slab by chance. These conditions made piling impossible and the yorkstone had to be dug out and the site reinstated, at a cost of $£ 20,000$. Since the contractor was responsible for ground conditions, the client's architect expected them to carry this cost. The contractor, however, argued that they had been instructed to price in accordance with a site investigation report which had been provided by the client. Both sides insisted that they were in the right and refused to back down. The immediate result was that work stopped and the site was abandoned for some time.

Eventually, the contractor moved a new project manager onto the job, who negotiated a compromise with the architect. This involved each side paying half the cost of the extra work. While this deal got the project moving again, it was not considered by the contractor to be a satisfactory outcome. As the new project manager put it: 
“We’ve done a fifty-fifty deal purely because we were desperate for money.

Not because we thought we were wrong, because we think we were right.”

The project manager showed the researcher a second claim he was pursuing, involving the misinterpretation of a drawing. The issue in contention concerned a detail in one corner of a crowded sheet, containing many similar details. The contractor had built the detail as drawn, overlooking the fact that a note adjacent to it instructed him not to build it, but to build a second detail instead. The mistake made subsequent work more expensive. While admitting that he had made a mistake, the project manager felt that it was an excusable one, due to the confusing nature of the drawing. He requested compensation for the extra expense. The client refused. Again, the project manager felt aggrieved and was continuing to pursue the claim.

\section{How Opportunities for Claims Arise}

It can be seen from the forgoing that there are several different kinds of reasons for claims. Unforeseen ground, or weather conditions will inevitably occur from time to time. Other problems too can arise from the fact that the site of production is new for each project and that projects do not take place on enclosed premises. Relations with neighbours, for instance, was often a major consideration on the projects in the study. This set of conditions is unique to construction and undoubtedly has an effect on the predictability of price. (Other industries face different variable conditions. It might be argued, for instance, that those faced by IT companies are comparable. While not faced with ground and weather conditions, these companies do have to perform discrete projects on the premises of other corporate bodies; they have, moreover, additional problems attendant on the complexity and fast changing nature of the technology and the need to fit each system to an individual client. If a 
common criticism of the construction industry is that the technology changes little and slowly, this might at least contribute to greater predictability of results.)

However, organizational conditions are clearly also important reasons for claims. Mistakes in calculating quantities, bad planning and ineffective communication have all been highlighted as reasons for the claims discussed in this paper. It is also the case that a procurement system which emphasises tender price as the sole or principle criterion of selection creates the conditions in which contractors are encouraged to plan for claims from the very inception of a project; a situation exacerbated in periods of economic recession in which 'buying work' by underbidding at tender stage may be commonplace.

Particular problems were found in the public sector, where three kind of pressure leading to inadequate design were noted. First, in evaluating tenders, consultants, especially in government service, experience considerable pressure to accept the lowest tender. It is often felt that any other course would leave the consultant open to charges of corruption. As one consultant put it, “questions would be asked”. Second, time pressures can arise towards the end of the financial year, when inflexible budgetary arrangements lead to the need to spend any remaining money in order to avoid losing it. Third, pressures from the numerous stakeholders that can be concerned with public works can lead to uncertainty as to the requirements of the design. As one engineer put it:

“[you have to] submit your designs to the butcher, the baker, the candle-stick maker and you wind up with seven different ways in which it may be done.”

The result of this process can be that the design is never fully completed; as intended for lump sum contracting (the norm in the building sector) if not to the same extent for measure and value contracting (the norm in civil engineering). 


\section{Discussion and Conclusion}

It may be objected that in reporting these findings, we have made no comment as to the justification, or otherwise, of the practices recorded. This has been a deliberate omission. Claims are variously justified and condemned throughout the industry and our readers will have their own views on these matters. We feel it would merely make accurate reporting more difficult, while adding nothing worthwhile to the analysis, to introduce our own opinions here.

It might also be objected that in making 'culture' our principal analytic device and in defining it so widely, we have produced an account that is analytically empty. The concept of 'culture', it might be argued, in covering everything, thus adds nothing to our account. It does no analytic work at all. However, this analytic neutrality is precisely what makes the definition useful to us. It is not intended as a tool for performing analysis on the data we have accumulated. This data consists in the analyses used by our informants themselves. To re-analyse it using concepts we ourselves introduce would be to contravene the strong requirement of unique adequacy. Rather, 'culture' for us is a covering concept, intended to insure industry members' own accounts of industry activities against external analytic distortion.

Moreover, this conceptual looseness at the outset makes it possible to focus on major features of this indigenous analysis and explore them in a holistic manner. These 
features are (1) the predictability of claims and (2) their utility in both proactive and reactive planning by contractors.

The finding that both proactive and reactive strategies are pursued raises the possibility of distinct variants of the claims culture. We have found evidence that strategy varies from company to company, project to project and even in some companies, from individual to individual. However, we lack sufficient data to give any systematic account of this variation. A further limitation of this report is that we are unable to give any clear idea of the prevalence of claims culture.

We have found evidence of this culture across a range of civil engineering and large construction projects; we have not investigated house building, or any process contracts.

On the other hand, there is considerable evidence (not reported here) that the claims culture is actively resisted. This is evident in such industry initiatives as the Latham (1993, 1994) and Egan (1998) reports and subsequent moves towards partnering and lean construction, as well as in the testimony of our informants. An analysis of the broader cultural context in which claims occur has been reported elsewhere (Rooke \& Seymour 2003). It is beyond the scope of our study to attempt an assessment of the current status of claims culture. What we are able to say is that any such assessment should bear in mind the following points. We have outlined the economic origins of the claims culture, but this should not be taken as an indication that economics are its only foundation. A principle foundation of any culture its familiarity to those who participate in it. The shared knowledge that a culture makes available to its members is a source of conservatism that often leads to practices surviving even when the utilitarian reasons for engaging in them have ceased to be effective. Furthermore, 
even if the practices cease entirely, the knowledge of those practices will not be forgotten. Thus, it may be that the culture will become dormant, able to reassert itself when conditions become more favourable.

5,220 words

\section{Acknowledgements}

The research reported in this paper was funded by the Engineering and Physical Sciences Research Council (project number GR/J90459).

\section{References}

Brown, A. (1995) Organisational Culture, Pitman Publishing, London.

Descartes, R. (1937) A Discourse on Method, Dent \& Sons, London.

Dietrich, M. (1994) Transaction Cost Economics and Beyond: towards a new economics of the firm, London: Routledge.

Egan, J. (1998) Rethinking construction: the report of the Construction Task Force 
to the Deputy Prime Minister, John Prescott, on the scope for improving the quality and efficiency of UK construction, Department of Trade and Industry, London.

Fisher, T. F. \& Ranashinge, M. (2001) 'Culture and Foreign Companies Choice of Entry Mode: The Case of the Singapore Building and Construction Industry' in Construction Management and Economics, 19:343-353.

Garfinkel, H. (1984) Studies in Ethnomethodology, Polity Press, Cambridge. Garfinkel, H. (2002) Ethnomethodology’s Program: Working out Durkheim's Aphorism, Rowman \& Littleford, Lanham.

Garfinkel, H. \& Wieder, D. L. (1992) 'Two Incommensurable, Asymmetrically Alternate Technologies of Social Analysis', in G. Watson \& R. M. Seiler (eds.), Text in Context, Sage, London, pp. 175-206.

Heyl, B. S. (2001) 'Ethnographic Interviewing', in P. Atkinson, A. Coffey, S.

Delamont, J. Lofland, \& L. Lofland (Eds.) Handbook of Ethnography, Sage, London. Hillebrandt, P. \& Cannon, J. (1990) The Modern Construction Firm, Macmillon, Houndmills.

Hofstede, G. (1980) Culture’s Consequences: International differences in workrelated values, Sage, London.

Latham, M. (1993) Trust and Money, HMSO, London.

Latham, M. (1994) Constructing the Team, HMSO, London.Mishler, E. G. (1986) Research Interviewing: context and narrative, Harvard University Press, London. Levi-Strauss, C. (1977) Structural Anthropology, C. Jacobson \& B. G. Schoepf (Trs.), Penguin, Harmondsworth. 
Martin, J. (2002) Organizational Culture: mapping the terrain, Sage, Thousand Oaks.

Parsons, T. (1951) The Social System, Routledge and Kegan Paul, London.

Raftery, J., McGeorge, D. \& Walter, M. (1997) ‘Breaking Up Methodological

Monopolies: a multi paradigm approach to construction management research', in Construction Management \& Economics, 15:291-297.

Robbins, S. P. (2001) Organizational Behaviour, Financial Times/Prentice Hall PTR, New Jersey

Rooke, J. \& Seymour, D. (1995) 'The NEC and the Culture of the Industry: Some Early Findings Regarding Possible Sources of Resistance to Change', Engineering, Construction and Architectural Management, 2:4.

Rooke, J., Seymour, D. \& Fellows, R. (2003) 'The Claims Culture; A Taxonomy of Industry Attitudes’, in Construction Management and Economics, 21:167-174.

Ryle, G. (1963) The Concept of Mind, Penguin, Harmondsworth.

Senior, B (2001) Organisational Change, Prentice Hall, New Jersey

Seymour, D. \& Rooke, J. (1995) 'The culture of the industry and culture of research', in Construction Management and Economics, 13:511-523.

Spradley, J. P. (1979) The Ethnographic Interview, Harcourt Brace Jovanovich, London.

Tam, C. M., Fung, I. W. H. \& Chan, A. P. C. (2001) 'Study of Attitude Changes in People After the Implementation of a New Safety Management System: The Supervision Plan’, in Construction Management and Economics, 19:393-403. 
Tylor, E. B. (1913) Primitive culture: researches into the development of mythology, philosophy, religion, art, and custom, Volume 1 , (5 $5^{\text {th }}$ edition) John Murray, London.

Williamson, O. E. (1985) The Economic Institutions of Capitalism: Firms, Markets, Relational Cotracting, New York: The Free Press.

Winch, P. (1990) The Idea of a Social Science and its Relation to Philosophy (second edition) Routledge and Kegan Paul, London.

Wittgenstein, L. (1958) Philosophical Investigations (second edition) Blackwell, Oxford. 